\title{
Experimental Study on the Materials and Performance of Diamond- impregnated Cutter
}

\author{
Yu Jinping ${ }^{1}$ Zou Deyong ${ }^{1, *}$, Wen Wu ${ }^{1,2}$ and Zhang Yin $^{3}$ \\ ${ }^{I}$ School of Petroleum Engineering, China University of Petroleum (East China), Qingdao, 266580, China \\ ${ }^{2}$ Urban Construction Investment Management Center of Xishui, Huanggang 438200, China \\ ${ }^{3}$ Department of Petroleum Engineering, University of Alaska Fairbanks, Fairbanks, Alaska, 99775, United States
}

Received 13 December 2020; Accepted 22 February 2021

\begin{abstract}
Rock-breaking efficiency and wear resistance of diamond-impregnated cutter (DIC) are important evaluation indexes of comprehensive rock-breaking performance. The comprehensive performance index of DIC is influenced by its composition and sintering method. A method for screening the material composition and testing the performance of DIC was proposed in this study to improve the rock-breaking efficiency and prolong service life of diamond-impregnated bit in hard stratum. In this method, through the establishment of the test model of DIC material, the performance of DIC prepared by different sintering methods were compared, and the DIC material suitable for hard formation was determined. Performance experiments were carried out to verify the rationality of calcining DIC with the addition of composite diamond particles with $60 \% \mathrm{WC}+15 \% \mathrm{FeCuXP}+25 \% \mathrm{CuSn}$ as basic material. Results show that the DIC calcined via hotpressing sintering demonstrates satisfactory wear resistance, high rock breaking efficiency, and long service life. Rate of penetration (ROP) and wear rate of single or composite grain size of DIC are positively correlated with diamond grain size. Small grain size indicates small ROP and wear rate. The comprehensive performance index of DIC with the single grain size is lower than that with composite grain size. The comprehensive performance index of the single grain size of DIC is only 0.91 , while that of composite grain size of DIC reaches 0.96 . This study can provide a theoretical reference for developing DIC with satisfactory wear resistance and high rock breaking efficiency.
\end{abstract}

Keywords: Diamond-impregnated cutter, Sintering, Rate of penetration, Wear resistance, Comprehensive performance

\section{Introduction}

Polycrystalline diamond compact (PDC) bits have been widely used in oil and gas drilling and development due to their satisfactory wear resistance and high rock breaking efficiency [1]. Bit manufacturers in countries, such as China, United States, and Canada, according to formation characteristics and drilling requirements, have developed different types of PDC bits with varying cutter shapes.

However, shallow surface oil and gas resources have become increasingly scarce with the continuous expansion of oil and gas exploration and development fields. Oil and gas resources in complex geological conditions and deep strata, such as shale gas and coalbed methane, have become important fields of land and sea exploration and development. Quartz sandstone, siliceous dolomite, and igneous rock, which demonstrate strong abrasiveness, high hardness, and poor drillability, exist in exploration and development projects of deep and ultradeep wells, such as shale gas and coalbed methane. Therefore, a diamondimpregnated bit suitable for such stratum is developed [2]. Developing a diamond-impregnated bit with strong wear resistance and high strength suitable for high-speed drilling in strong abrasive stratum is urgently necessary to develop high-efficiency diamond bits, improve rock breaking efficiency, and reduce cost.

Scholars in the field of bit development and production

*E-mail address: eugene_yujp@126.com

ISSN: 1791-2377 @ 2021 School of Science, IHU. All rights reserved. doi:10.25103/jestr.141.15 have carried out various studies on bit cutters. Bits are mainly developed based on bit cutter structure and layout to improve their rock-breaking efficiency and prolong the drilling bit service life [3-6]. Although the rate of penetration (ROP) and wear resistance of bits are closely related to the structure and layout of cutters, the wear resistance, strength, and hardness of cutters are also influenced by their material composition and sintering mode. Selecting the cutter material, sintering mode, and test model plays a key role in the process of bit development. Therefore, the selection process of the diamond-impregnated cutter (DIC) material suitable for hard stratum, determination of the sintering method of DIC, and development of DIC with high rock breaking efficiency and satisfactory wear resistance are still urgent problems that must be solved in the field of bit development.

With the hardness, strength and compactness of DIC as evaluation indexes, the properties of DIC were tested, and the best matrix material and the most suitable sintering method were optimized. The wear resistance and rock breaking efficiency of DIC were tested using a test bench, and the mixture ratio of DIC matrix material formula and diamond grain size were determined to form a new DIC. The test results of the new DIC were compared and analyzed to select a suitable DIC for hard stratum. This study provides a design method and experimental basis for designing DICs suitable for hard formations. 


\section{State of the Art}

Different drill bits suitable for drilling hard strata are needed with the continuous expansion of the oil and gas exploration field. Scholars in the drill bit development industry have established PDC drill bits using different methods. Yu et al. [7] designed a new hybrid bit with PDC and DIC cutting unit to improve the rock-breaking efficiency, prolong the service life of PDC bit in hard ground with strong abrasiveness, remarkably improve the drilling efficiency, and reduce the drilling cost. This hybrid bit passed the field test verification, but the study process and method of the DIC material were not presented. Niu et al. [8] proposed a hybrid and disk-shaped hybrid drill bit to meet drilling requirements of hard strata. The key component of this drill bit is a disk-shaped insert that demonstrates comprehensive advantages of conventional PDC and disk-shaped roller cone bits. Although this drill bit was experimentally investigated, the study method of the disk-shaped insert was excluded. Kuniyuki et al. [9] experimentally explored the rockbreaking efficiency, wear resistance of PDC bits in special hard stratum rocks, and proposed the change of drilling parameters to adapt to stratum lithology, improve the rockbreaking efficiency, and reduce the wear rate. However, material properties and study methods of bit teeth were not discussed. $\mathrm{Yu}$ et al. [10] simulated and calculated rock dynamic stress during PDC bit drilling and investigated the relationship between the rock breaking process of PDC bit and bit structure from the mechanical perspective, but material properties of bit teeth were excluded. Kamatov et al. [11] pointed out that the composite bit is more effective for frequently interbedded bottom layers, such as deep shale, siltstone, limestone, and dolomite, using an engineering test but failed to present the specific structure of the composite bit. Alexis [12] argued that a hybrid drill bit is suitable for drilling in hard strata and combined PDC and cutting elements, such as diamond, to meet basic requirements for drilling in rock strata with high compressive strength, strong wear resistance, and low drillability; however, the material problem of the hybrid cutting element was ignored. He [13] proposed a finite element method to shorten the study period of the rock-breaking mechanism of personalized PDC bits and simulate the rock-breaking mechanism of personalized PDC bits combined with experiments and explored the rockbreaking process of tapered teeth of personalized PDC bits. However, this study focused on the influence of bit structure on bit wear and rock-breaking efficiency but ignored the composition of cutting elements. Agawani et al. [14] combined PDC and tungsten carbide inserts and designed a multifunctional drill bit with excellent impact resistance suitable for heterogeneous carbonate formations. Although tungsten carbide inserts were proposed, their components and screening methods were not discussed. Mazen et al. [15] and $\mathrm{Yu}$ [16] emphasized the importance of the bit structure. Mazen et al. [15] investigated the relationship between the bit structure, rock properties and PDC bit wear resistance and established a mathematical model for predicting the bit wear resistance. However, the study focused on bit wear and tooth material design. $\mathrm{Yu}$ [16] emphasized the rational layout of PDC and DIC cutting elements to improve the penetration rate and prolong the service life of drill bits. Although DIC was discussed, the composition of DIC was not mentioned. Abbas and Musa [17] argued that complex stratum structures need personalized PDC bits. The rationality and accuracy of infrared spectrum analysis of wear resistance of the PDC bit were proven via experiments.
The personalized bit design and rock breaking mechanism were combined, but the structure and composition of bit teeth were not discussed. Wang et al. [18] established a three-dimensional dynamic model of bit rock breaking, explored the rock breaking law, and designed the bit structure based on measured rock mechanical properties. However, the scholars failed to propose a design method for integrating multiple cutting elements. Saksala et al. [19] simulated rock breaking on a bit-rock coupling model and examined the relationship between impact velocity and rock breaking efficiency by combining numerical simulation and experimental approaches but failed to introduce cutting metamaterials and the study method. Abbas [20] reviewed wear problems of oil bits and calculated the wear loss via simulation. However, bit geometry and rock breaking mechanism were not described, let alone the material and method for designing bit teeth. Wang et al. [21] determined the tooth layout structure and mode of PDC bits in granite and hard sandstone interbedded formation through laboratory experiments, assessed the influence of the cutter layout structure on service life and penetration rate, and proposed the design method of PDC bit tooth structure. However, experimental basis and selection of cutting tooth materials were excluded. Galarraga et al. [22] emphasized the importance of developing special bits suitable for hard, abrasive, and thick conglomerate and sandstone intervals. Special bits were tested in practical projects. However, the bit structure, composition, and screening method of bit tooth materials were excluded because of technical confidentiality.

These studies proposed new viewpoints on PDC bit structure, cutter layout mode, and integration of cutting elements as well as discussed requirements for high strength and wear resistance of bits in hard stratum. Several investigations put forward the viewpoint of integration design of cutting elements. However, few studies have focused on screening DIC materials through experiments or determining the sintering method and composition of cutting elements based on experimental data. This study proposed a new method for developing DIC through experimental analysis and comparison. Basic requirements for the performance of DIC in hard stratum were analyzed. A matrix test model of DIC was established, and comparative analysis was carried out for test data of DICs with different diamond grain sizes. The results can provide an experimental basis for determining the sintering method of DIC, screening DIC materials, and designing DIC suitable for hard stratum.

The remainder of this study is organized as follows. Basic requirements of hard stratum for the DIC performance are analyzed, the matrix material formula and test model of DIC are established, the test model and calcination method of DIC materials are determined, and performance calculation and test methods of DIC are proposed in Section 3. The relationship between DIC and ROP and wear resistance of drill bit is obtained by analyzing the test results of DIC matrix materials and comparing test data of DICs with different diamond grain sizes in Section 4. Finally, the study is summarized and conclusions are drawn in Section 5.

\section{Methodology}

\subsection{Pre-alloyed powder material formula of the DIC matrix}

The two kinds of DIC matrix structure models are rectangular and circular cross-section matrix structure 
models, as shown in Figs. 1(a) and 1(b), respectively. The two matrix structure models are used in different situations. The rectangular cross-section matrix structure is used to test and compare the matrix performance and the screen matrix material formula, while the circular cross-section matrix structure is utilized in the calcine-DIC to test and determine the rock-breaking efficiency of the DIC.

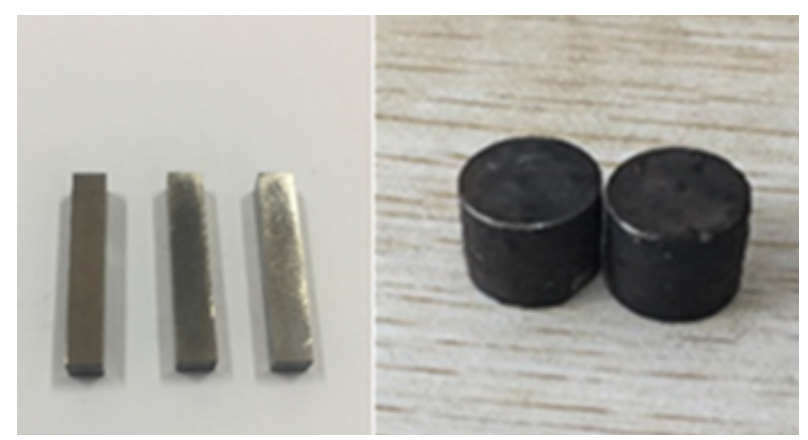

(a) Hexagonal matrix model, (b) Cylindrical matrix model

Fig. 1. Matrix models of the DIC

The DIC matrix performance should meet the following requirements: (1) high strength and hardness to ensure the service life of DIC when drilling hard strata, (2) satisfactory self-sharpening to expose diamonds continuously and maintain constant ROP of the diamond-impregnated bit during drilling, and (3) sufficient compactness and the better holding force between matrix and diamond to ensure that diamond particles will not easily fall off from the matrix.

Analysis of characteristics of metal carbide material (WC) demonstrated its high elastic modulus, hardness, and wear resistance; satisfactory thermal conductivity and formability; and linear expansion coefficient close to that of the diamond. The WC material exhibits strong adaptive ability for hard ground with strong abrasiveness. The matrix formed by mixing and sintering $\mathrm{WC}$ as the basic material with copper- and iron-based binders can meet mechanical and rock-breaking properties of DIC.

Three kinds of iron-based binders, one kind of copperbased binder, and the WC material are mixed as the prealloyed powder of the DIC matrix material, as shown in Fig. 2. Figs. 2(a)-2(d) show the X6-600 pre-alloyed, YA321 prealloyed, FAM1031 pre-alloyed, and $\mathrm{CuSn}$ conventional alloy powders. Pre-alloyed powder components and their physical properties are listed in Tables 1 and 2, respectively.

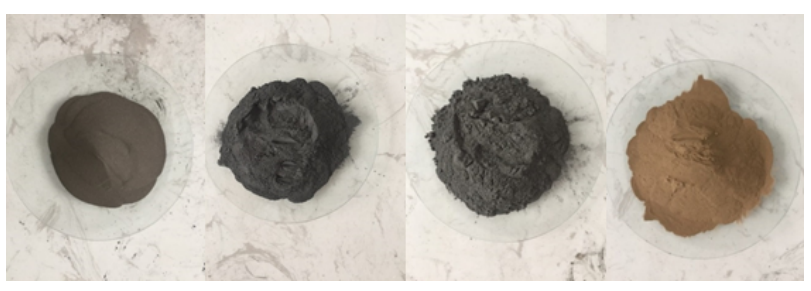

(a) X6-600, (b) YA321, (c) FAM1031, (d) CuSn20

Fig. 2. Matrix models of the diamond-impregnated cutter

Table 1. Components of pre-alloyed powder

\begin{tabular}{l|l}
\multicolumn{1}{c}{$\begin{array}{c}\text { Pre-alloyed } \\
\text { powder }\end{array}$} & \multicolumn{1}{c}{ Composition (percentage) } \\
\hline X6-600 & $\mathrm{Fe} \mathrm{(62)} \mathrm{Cu}(11) \mathrm{Co} \mathrm{(17)} \mathrm{Sn}(5) \mathrm{P}(5)$ \\
YA321 & $\mathrm{Fe} \mathrm{(64)} \mathrm{Cu} \mathrm{(16)} \mathrm{Co} \mathrm{(20)}$ \\
FAM1031 & $\mathrm{Fe} \mathrm{(80)} \mathrm{Ni} \mathrm{(18)} \mathrm{Co} \mathrm{(2)}$ \\
\hline
\end{tabular}

Table 2. Performance of X6-600, YA321, and FAM1031

\begin{tabular}{|c|c|c|c|c|c|c|}
\hline Pre-alloyed powder & $\begin{array}{c}\text { Sintering } \\
\text { temperature }\left({ }^{\circ} \mathrm{C}\right)\end{array}$ & $\begin{array}{c}\text { Loose density } \\
\left(\mathrm{g} / \mathrm{cm}^{3}\right)\end{array}$ & $\begin{array}{c}\text { Theoretical } \\
\text { density }\left(\mathrm{g} / \mathrm{cm}^{3}\right)\end{array}$ & $\begin{array}{c}\text { Rockwell } \\
\text { hardness (HRB) }\end{array}$ & $\begin{array}{c}\text { Bending strength } \\
\text { (MPa) }\end{array}$ & $\begin{array}{c}\text { Oxygen } \\
\text { content }(\%)\end{array}$ \\
\hline X6-600 & 780 & $\leq 3.0$ & 7.87 & $100-110$ & $1100-1400$ & $\leq 0.23$ \\
\hline YA321 & $800-880$ & $3.0-3.4$ & 8.2 & $100-105$ & $1400-1700$ & $\leq 0.28$ \\
\hline FAM1031 & $720-920$ & 2.1 & 8.05 & $88-91$ & $900-1200$ & $0.3-0.5$ \\
\hline
\end{tabular}

\subsection{Matrix firing and mechanical analysis model of the diamond-impregnated cutter}

By comparing the performance of DIC calcined by two different sintering methods, the cold-pressing sintering and hot-pressing sintering, the suitable sintering method was optimized.

The matrix structure in hot-pressing sintering is a hexahedron with a dimensions of $5 \mathrm{~mm} \times 5 \mathrm{~mm} \times 30 \mathrm{~mm}$ (Fig. 1[a]). The matrix mold and clamping tool are shown in Figs. 3(a) and 3(b), respectively, and the sintering furnace used for hot-pressing calcination is presented in Fig. 3(c).

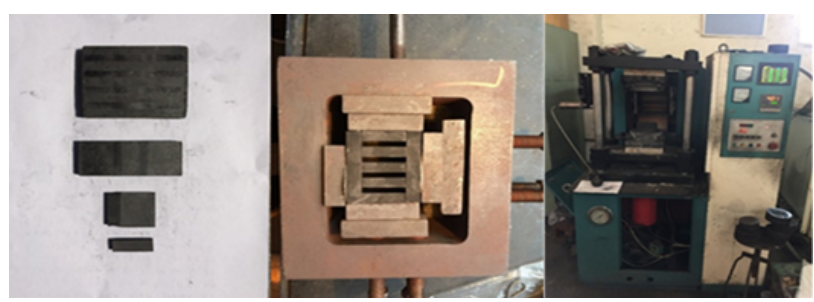

(a) Graphite mold, (b) matrix fixture, (c) RJY2000A sintering machine Fig. 3. Hot-pressing sintering mold and furnace

The matrix structure in cold-pressing sintering is a cylinder with a size of $\varphi 16 \times 10 \mathrm{~mm}$ (Fig. 1[b]). The matrix pressing mold, matrix sintering graphite mold, and sintering furnace for sintering with cold pressing are illustrated in Figs. 4(a), 4(b), and 4(c), respectively.

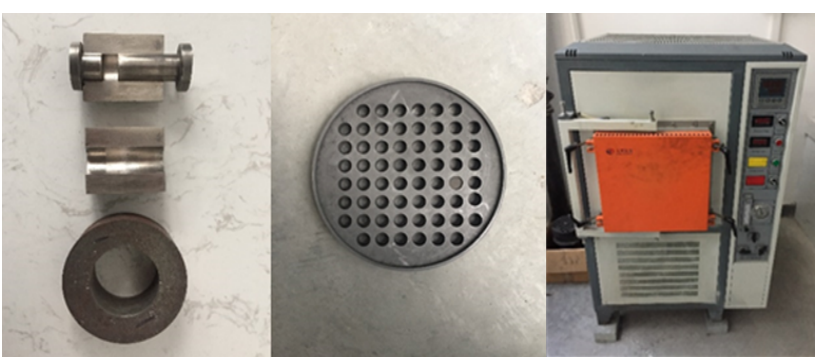

(a) Matrix steel mold, (b) Graphite mold, (c) Vacuum sintering furnace Fig. 4. Cold-pressing calcination model and sintering furnace

The powder of each component was first mixed for 8 hours, pressed and molded in a graphite grinding tool, and finally sintered in the RJY2000A sintering machine and vacuum sintering furnace in the process of matrix sintering.

Cold- and hot-pressing matrix sintering methods have different sintering processes.

The metal powder is molded by pressing at room temperature with a pressing pressure of $200 \mathrm{MPa}$ in coldpressing sintering. The matrix is sintered as follows: (1) Heating is applied from room temperature to $500{ }^{\circ} \mathrm{C}$ at a heating rate of $5{ }^{\circ} \mathrm{C} /$ minute. (2) The temperature is maintained for 1 hour to ensure that the vaporized plasticizer 
can be fully discharged from the vacuum furnace. (3) The matrix is heated to the set sintering temperature at a heating rate of $10{ }^{\circ} \mathrm{C} /$ minute. (4) The temperature is maintained for 3 hours. (5) Heating is stopped and the matrix is cooled. The matrix is pressed and heated in the uniaxial direction in hotpressing matrix sintering to ensure that molding and sintering are completed simultaneously.

Heating and pressing are carried out simultaneously in the hot-pressing sintering method. The thermoplastic state of the powder contributes to contact diffusion and flow mass transfer of particles. Therefore, the forming pressure is significantly lower than that of the cold-pressing method. Sintering parameters are set as follows: sintering temperature, $900{ }^{\circ} \mathrm{C}$; sintering pressure, $30 \mathrm{MPa}$; and heat preservation, 5 minutes

Although the DIC matrix performance is related to the sintering temperature and pressure, the matrix composition plays a decisive role. WC is the main material and the alloy powder is composed of the metal binder and additive, which are fully mixed according to a certain proportion, in the formula of the matrix material of DIC (Table 3). The matrix is fired via cold- and hot-pressing sintering methods. Tables 3 list nine different matrix formulas and Table 4 lists the sintering parameters corresponding to each matrix formula. Different matrices can be obtained under different sintering methods and temperatures. Matrix formulas and sintering methods are screened via mechanical performance experiments and theoretical calculation

Table 3. Matrix formulas

\begin{tabular}{l|l}
\hline Serial number & Matrix formula \\
\hline 1 & $60 \% \mathrm{WC}+25 \% \mathrm{FeCuXP}+15 \% \mathrm{CuSn}$ \\
2 & $60 \% \mathrm{WC}+20 \% \mathrm{FeCuXP}+20 \% \mathrm{CuSn}$ \\
3 & $60 \% \mathrm{WC}+15 \% \mathrm{FeCuXP}+25 \% \mathrm{CuSn}$ \\
4 & $60 \% \mathrm{WC}+25 \% \mathrm{FeCoCu}+15 \% \mathrm{CuSn}$ \\
5 & $60 \% \mathrm{WC}+20 \% \mathrm{FeCoCu}+20 \% \mathrm{CuSn}$ \\
6 & $60 \% \mathrm{WC}+15 \% \mathrm{FeCoCu}+25 \% \mathrm{CuSn}$ \\
7 & $60 \% \mathrm{WC}+25 \% \mathrm{FeNiCo}+15 \% \mathrm{CuSn}$ \\
8 & $60 \% \mathrm{WC}+20 \% \mathrm{FeNiCo}+20 \% \mathrm{CuSn}$ \\
9 & $60 \% \mathrm{WC}+15 \% \mathrm{FeNiCo}+25 \% \mathrm{CuSn}$ \\
\hline
\end{tabular}

Table 4. Sintering parameters of each formula

\begin{tabular}{l|l|c|c}
\hline $\begin{array}{l}\text { Serial } \\
\text { number }\end{array}$ & $\begin{array}{l}\text { Sintering } \\
\text { temperature }\left({ }^{\circ} \mathbf{C}\right)\end{array}$ & $\begin{array}{l}\text { Sintering } \\
\text { pressure (MPa) }\end{array}$ & $\begin{array}{l}\text { Holding } \\
\text { time } \\
\text { (minute) }\end{array}$ \\
\hline 1 & $820,860,900,940$ & & \\
2 & $820,860,900,940$ & & \\
3 & $820,860,900,940$ & & \\
4 & $860,900,940,980$ & & 5 \\
5 & $860,900,940,980$ & 30 & \\
6 & $820,860,900,940$ & & \\
7 & $820,860,900,940$ & & \\
8 & $860,900,940,980$ & & \\
9 & $860,900,940,980$ & & \\
\hline
\end{tabular}

The DIC matrix must demonstrate sufficient strength, hardness, compactness, and diamond holding power, which are related to the sintering method of the matrix formula, to ensure the excellent performance of the DIC. The matrix structure is a cuboid with a rectangular cross section to facilitate the matrix strength test. The bending strength of the matrix is calculated as follows:

$$
\sigma_{b}=\frac{3 P L}{2 b h^{2}}
$$

where

$$
\begin{aligned}
& \sigma_{b} \text {-bending strength, } \mathrm{MPa} ; \\
& P \text {-breaking load, } \mathrm{N} ; \\
& L \text {-fulcrum spacing, } \mathrm{mm} ; \\
& b \text {-sample width, } \mathrm{mm} \text {; and } \\
& h \text {-sample height, } \mathrm{mm} \text {. }
\end{aligned}
$$

The decline rate of the bending strength is used to reflect the holding force of the matrix on the diamond after measuring bending strengths of the matrix and DIC. The decline rate of the bending strength of the matrix is expressed as follows:

$$
q=\frac{\sigma_{b}-\sigma_{D}}{\sigma_{b}}
$$

where $q$-decline rate of the bending strength, $\%$;

$\sigma_{b}$-bending strength of matrix without diamond particles, MPa;

$\sigma_{D}$-bending strength of matrix with diamond particles, MPa.

A Rockwell hardness tester HR150-DT was used to test the hardness of the matrix. The compactness of different formulas under different sintering processes was calculated as follows:

$$
D=\frac{\rho}{\rho_{0}}
$$

where $D$-compactness, $\%$;

$$
\begin{aligned}
& \rho \text {-actual density, } \mathrm{g} / \mathrm{cm}^{3} ; \\
& \rho_{0} \text {-theoretical density, } \mathrm{g} / \mathrm{cm}^{3} \text {. }
\end{aligned}
$$

The ratio of penetration rate to wear rate is a comprehensive performance index in engineering and an important index for evaluating the rock-breaking performance of DIC. A large comprehensive performance index indicates the improved rock-breaking performance of DIC. The comprehensive performance index of DIC is expressed as follows:

$$
C P I O B=\frac{R O P}{R O W}
$$

where $C P I O B$-comprehensive performance index of bit, \%; $R O P$-rate of penetration, $\mathrm{m} / \mathrm{h}$; $R O W$-rate of wear, $\mathrm{g} / \mathrm{s}$.

3.3 Models of diamond-impregnated cutters with different diamond grain sizes

No. 3 material $(60 \% \mathrm{WC}+15 \% \mathrm{FeCuXP}+25 \% \mathrm{CuSn})$ was selected as the matrix material formula of DIC, and the DIC was prepared via hot-pressing sintering method according to experiments of matrix sintering and mechanical properties. Based on the matrix material formula, various diamond particles were mixed thoroughly and then sintered into DIC models with different diamond grain sizes. Performance comparison experiments were carried out to analyze the performance of DIC with different diamond grain sizes and determine diamond parameters. Table 5 presents the formula of diamond parameters with different grain sizes. 
Table 5. Diamond grain size parameters

\begin{tabular}{l|l|l}
\hline & Serial number & Diamond parameters \\
\hline Single grain size & 1 & $100 \%$ concentration, $20 / 25$ mesh \\
& 2 & $100 \%$ concentration, 30/35 mesh \\
& 3 & $100 \%$ concentration, $40 / 45$ mesh \\
& 4 & $100 \%$ concentration, 50/60 mesh \\
\hline Composite grain size & 1 & $20 / 25 \mathrm{mesh}(30 \%)+30 / 35 \mathrm{mesh}(40 \%)+40 / 45 \mathrm{mesh}(30 \%)$ \\
& 2 & $20 / 25 \mathrm{mesh}(30 \%)+30 / 35 \mathrm{mesh}(40 \%)+50 / 60 \mathrm{mesh}(30 \%)$ \\
& 3 & $20 / 25 \mathrm{mesh}(30 \%)+40 / 50 \mathrm{mesh}(40 \%)+50 / 60 \mathrm{mesh}(30 \%)$ \\
& 4 & $40 / 50 \mathrm{mesh}(30 \%)+40 / 50 \mathrm{mesh}(40 \%)+50 / 60 \mathrm{mesh}(30 \%)$ \\
\hline
\end{tabular}

\subsection{Experimental model of the diamond-impregnated} cutter performance

The wear resistance, bending strength, holding force, and penetration rate of DIC are important performance evaluation indexes. The most direct performance evaluation method for DIC is test. The test model of DIC is shown in Fig. 5. The DIC hardness tester is presented in Fig. 6.

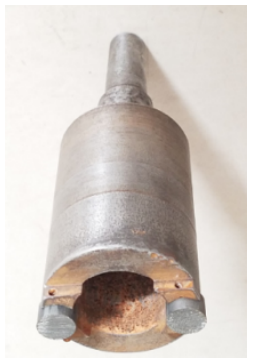

Fig. 5. Test model of performance of DIC

Fig. 6. Hardness tester
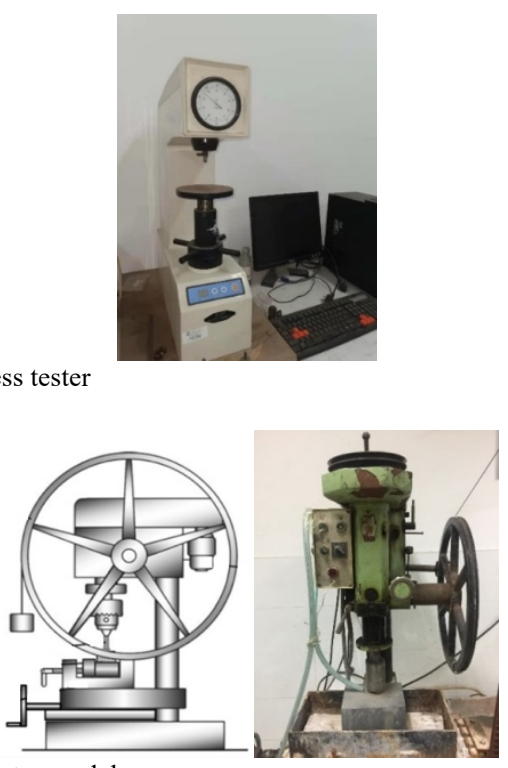

Figs. 7(a) and 7(b) show the penetration rate testing machine model and testing machine, respectively. A ROP testing machine was used to test and analyse the comprehensive performance of the DIC, screen the sintering method, and determine the formula of the DIC.

\section{Result Analysis and Discussion}

\subsection{Analysis and determination of the matrix sintering method}

In the comparative experiment of sintering, the No. 3 formula $(60 \% \mathrm{WC}+15 \% \mathrm{FeCuXP}+25 \% \mathrm{CuSn})$ was selected as the DIC matrix. Table 6 lists the hardness and compactness of No. 3 matrix material when different sintering methods are used.

Analysis of the cold-pressing sintering method: The hardness and density of the matrix sintered via the coldpressing method increase, with a maximum density of $82.3 \%$, as the temperature rises. This finding indicated that the matrix sintering is incomplete and the metallurgy and alloying degree is low. The minimum hardness of 102.5 HRB fails to meet the requirement for the DIC hardness in hard stratum.

Analysis of the hot-pressing sintering method: The density of the matrix sintered via the hot-pressing method is $99.1 \%$, which is close to the theoretical density of $100 \%$. This finding indicated that the alloy powder can be completely alloyed and metallurgically sintered via hot pressing. The maximum hardness of the matrix sintered via the hot-pressing method is $48.4 \mathrm{HRC}$, which is significantly higher than that of the matrix sintered via cold pressing and meets the requirements for the DIC hardness in hard stratum.

The comparison results showed that the DIC matrix sintered via cold pressing can meet the requirements for hardness and compactness of the DIC in hard stratum better than that sintered via hot pressing.

Fig. 7. ROP tester model

Table 6. Comparison of hardness and compactness under different sintering methods

\begin{tabular}{l|l|l|l|l|l}
\hline \multicolumn{2}{l|}{ DIC sintered by cold-pressing } & \multicolumn{3}{l}{ DIC sintered by hot-pressing } \\
\hline Sintering temperature $\left({ }^{\circ} \mathbf{C}\right)$ & Hardness (HRB) & Compactness (\%) & Sintering temperature $\left(^{\circ} \mathbf{C}\right)$ & Hardness (HRB) & Compactness (\%) \\
\hline 900 & 66.8 & 70.1 & & & \\
940 & 75.3 & 74.4 & 900 & 48.4 & \\
980 & 87.6 & 79.8 & & & \\
1020 & 102.5 & 82.3 & & \\
\hline
\end{tabular}

\subsection{Analysis of test results of the DIC matrix}

Fig. 8 presents the comparison of the hardness of DIC and matrix of nine material formulas sintered by hot-pressing. Fig. 9 shows the bending strength of nine matrixes without diamond and DICs with diamond.

Although the hardness of matrix of No.3 material formula $(60 \% \mathrm{WC}+15 \% \mathrm{FeCuXP}+25 \% \mathrm{CuSn})$ is not the highest, the hardness of DIC is the highest. The DIC and the matrix sintered via hot-pressing sintering method demonstrate high hardness, but the decline rate of the bending strength of the matrix is the smallest, as shown in Fig. 10 Hence, No. 3 material $(60 \% \mathrm{WC}+15 \% \mathrm{FeCuXP}+25 \% \mathrm{CuSn})$ formula is suitable for bedrock hard stratum. 


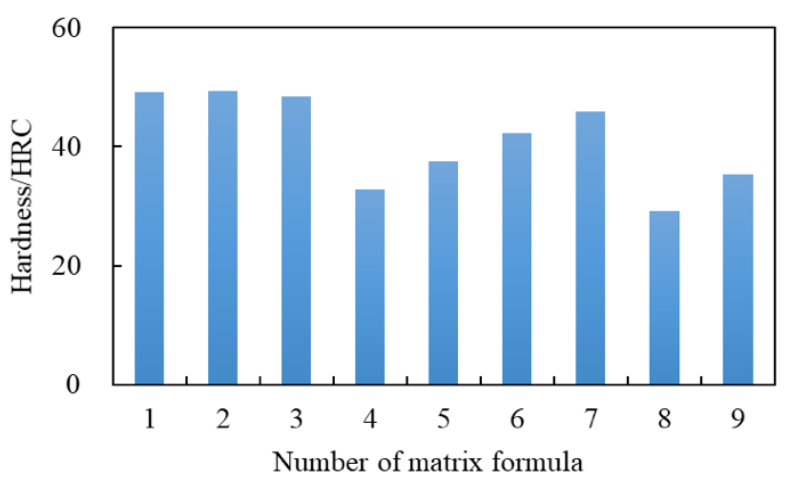

Fig. 8. Check whether this need not be presented in bold font. Apply possible corrections to similar instances in the study.

Fig. 9 shows the bending strength of nine matrixes without diamond and DICs with diamond. Fig. 10 shows the decline rate of the bending strength of the matrix of nine material formulas by calculated the data in Fig. 9. The decline rate of the bending strength of the matrix of No. 3 material $(60 \% \mathrm{WC}+15 \% \mathrm{FeCuXP}+25 \% \mathrm{CuSn})$ is the minimum at only $14 \%$.

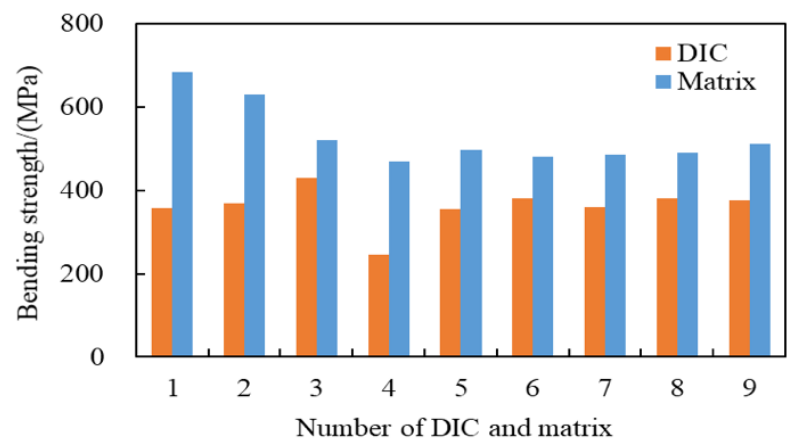

Fig. 9. Bending strength of nine matrixes without diamond and DICs with diamond

According to Figs. 8, 9 and 10, No. 3 material $(60 \% \mathrm{WC}+15 \% \mathrm{FeCuXP}+25 \% \mathrm{CuSn})$ formula is suitable for sintering DICs.

According to Reference [23], the strength of diamond particles is influenced by both temperature and holding time (Fig. 11). Tables 4 and 6 and Figs. 8, 9 and 10 show that the holding time of hot-pressing sintering is approximately 5 minutes to ensure that diamond particles have sufficient strength. Hence, the performance of the DIC meets the ideal requirements.

4.3 Test analysis of performance of diamondimpregnated cutters with different diamond grain sizes According to the analyses in Sections 4.1 and 4.2, the hotpressing sintering method is selected and the sintering temperature is controlled within $980{ }^{\circ} \mathrm{C}$ when comprehensive indexes, such as hardness, strength, strength decline rate, and diamond particle strength, are considered.
Diamond particles are added to No. 3 material $(60 \% \mathrm{WC}+15 \% \mathrm{FeCuXP}+25 \% \mathrm{CuSn})$, and the DIC is sintered. The performance of the DIC with different diamond grain sizes is tested, and the rock breaking performance is analyzed.

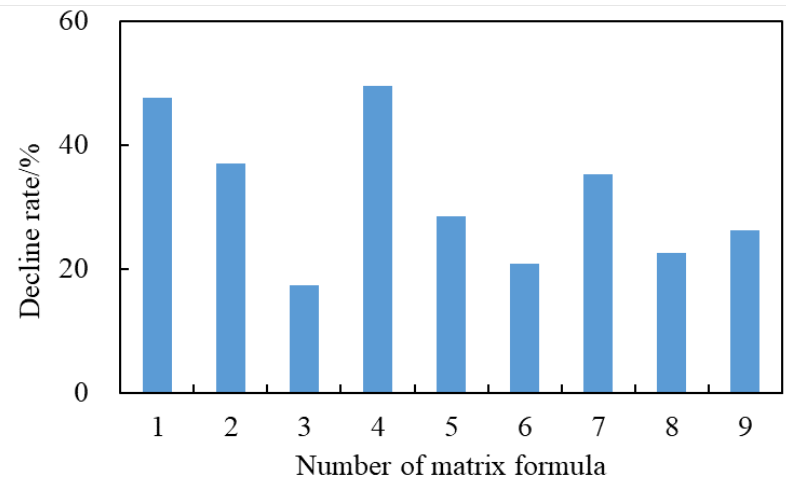

Fig. 10. Column diagram of the decline rate of the bending strength of the matrixes.

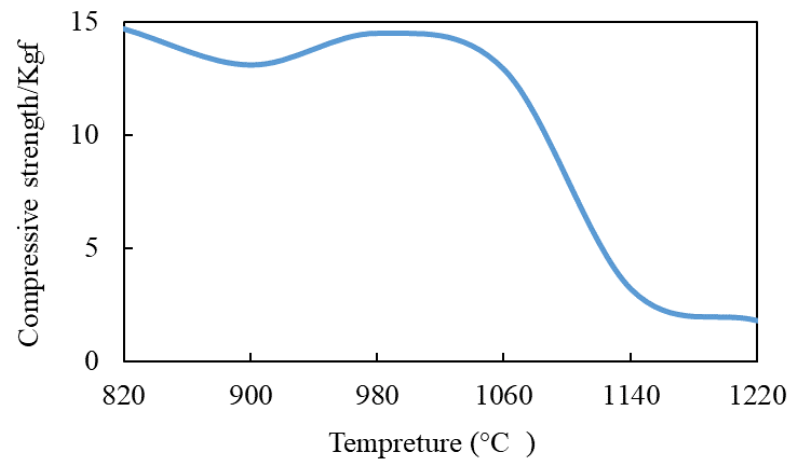

Fig. 11(a). Relationship between the diamond particle strength and the temperature

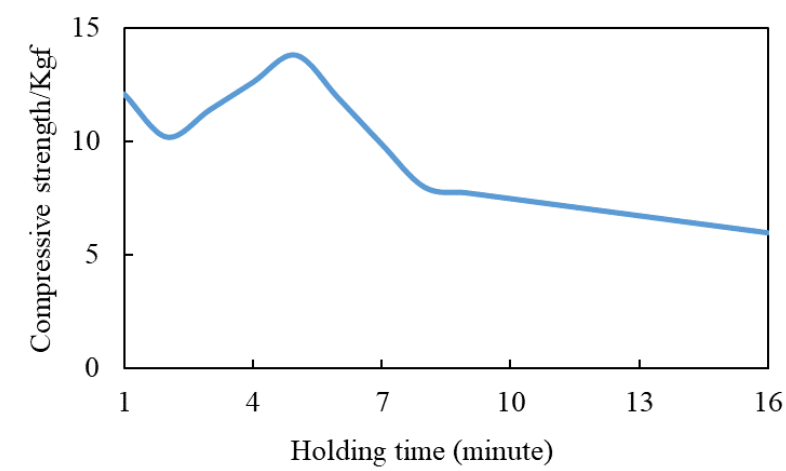

Fig. 11(b). Relationship curve between the diamond particle strength and the heat preservation time

Table 7 shows the relationship between DIC with different diamond parameters and the drilling depth, penetration rate, wear loss, and wear rate.

Table 7. Experimental data at different diamond parameters

\begin{tabular}{l|l|l|l|l|l|l}
\hline & Serial number & Wear loss (g) & Drilling depth (mm) & Drilling time (s) & ROP (m/h) & Wear rate (mg/s) \\
\hline & 1 & 0.1504 & 40.7 & 72 & 2.04 \\
Single grain size & 2 & 0.0835 & 37.67 & 104 & 2.09 \\
& 3 & 0.0325 & 36.69 & 152 & 0.80 \\
& 4 & 0.0162 & 42.95 & 303 & 0.87 \\
Composite grain size & 1 & 0.1303 & 48.96 & 102 & 0.21 \\
& 2 & 0.1094 & 59.22 & 138 & 1.73 \\
& 4 & 0.0677 & 44.1 & 142 & 1.21 \\
\\
\hline
\end{tabular}


Fig. 12 shows the relationship between the diamond grain size and ROP of the DIC. ROP of the DIC reduces with the decrease of the diamond grain size when diamond particles are single grain size. This finding indicated that diamond particles on the working face of the DIC and contact area with rock increase while the pressure on each diamond particle, load of the drilled rock, depth of the diamond particles drilling into the rock, and ROP of the DIC decrease. ROP of the DIC slightly reduces with the decrease of the diamond grain size when the diamond parameter is composite grain size. This finding indicated that the rock breaking efficiency of DIC with the composite diamond grain size is higher than that of the single grain size of DIC.

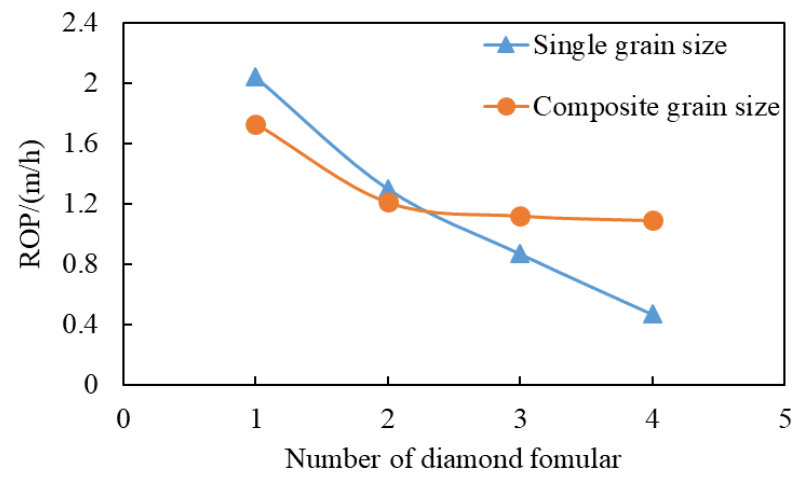

Fig. 12. Relationship curve between diamond grain size and ROP of diamond-impregnated cutter

Table 7 and Fig. 13 show that the wear rate of DIC with single grain size is larger than that with composite grain size when the diamond grain size is large. The wear rate of DIC with single grain size is smaller than that with composite grain size and the wear rate curves of the two kinds of DIC demonstrate intersection points, that is, wear rates are the same as the grain size decreases. The wear rate is an important analysis index of the wear resistance.

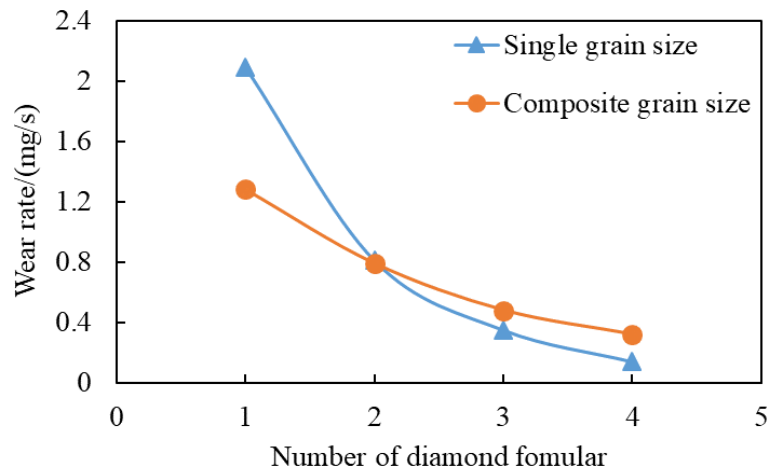

Fig. 13. Influence of the diamond grain size on the wear rate of the diamond-impregnated cutter

The rock-breaking performance of DIC can be evaluated using different parameters in addition to the ROP and wear rate. Figs. 12 and 13 illustrate that although the DIC with high ROP and low wear rate is the most suitable, it does not exist. Therefore, ROP and wear rate should be comprehensively analyzed when selecting diamond parameters. A large ROP indicates a small the wear rate, large comprehensive performance index, and enhanced rockbreaking performance of DIC. Comprehensive performance indexes of DIC are calculated according to the data in Table 7 and Equation (4) and the histogram is shown in Fig. 14.

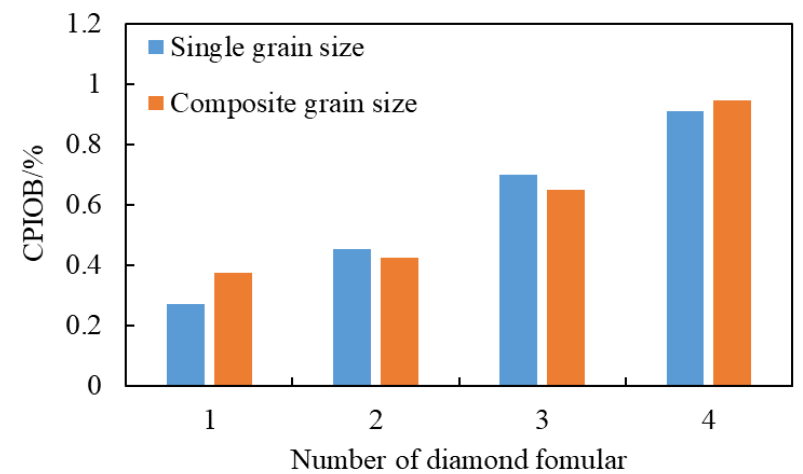

Fig. 14. Comprehensive performance of the diamond-impregnated cutter with different diamond parameters

According to Fig. 14, the comprehensive performance indexes of No. 4 DIC with single grain size and No. 4 DIC with composite grain size are the highest at 0.91 and 0.96 , respectively. The comparison of comprehensive performance indexes of DICs with single and composite grain sizes demonstrated that No. 4 DIC with composite grain size exhibits the highest comprehensive performance index.

\section{Conclusions}

A new method for screening and designing the DIC material formula was proposed in this study with experimental analysis and comparison to develop DIC with high rockbreaking efficiency and long service life suitable for hard stratum. Experimental models of the diamond matrix material, DIC material, and sintering method were established and experimental data of the matrix material were examined by analyzing the requirements of the performance of DIC in hard stratum. Moreover, the DIC material and sintering method suitable for hard stratum were determined. The following conclusions could be drawn:

(1) The DIC calcined via hot-pressing sintering method demonstrates satisfactory wear resistance, high rock breaking efficiency, and long service life with $60 \% \mathrm{WC}+15 \% \mathrm{FeCuXP}+25 \% \mathrm{CuSn}$ as the basic material and the addition of diamond particles.

(2) ROP of both DICs with single and composite grain sizes is positively correlated with the diamond grain size. A small grain size indicates a small ROP.

(3) The wear resistance of both DICs with single and composite grain sizes is negatively correlated with the diamond grain size. Meanwhile, the wear rate of DIC is positively correlated with the diamond grain size. A small diamond grain size indicates a small wear rate and long service life.

(4) The comprehensive performance index of DIC with single grain size is lower than that with composite grain size. The comprehensive performance index of DIC with single grain size is only 0.91 , while that of DIC with composite grain size can reach 0.96 .

DIC with high rock breaking efficiency, strong wear resistance, and high comprehensive performance index is designed in this study according to the basic theory of strength, hardness, density, and comprehensive performance index of DIC through the experimental method. Based on experimental data, $60 \% \mathrm{WC}+15 \% \mathrm{FeCuXP}+25 \% \mathrm{CuSn}$ was selected as the basic material and diamond particles were 
added to sinter the DIC. The comprehensive performance comparison of results demonstrated that the DIC calcined with the addition of $60 \% \mathrm{WC}+15 \% \mathrm{FeCuXP}+25 \% \mathrm{CuSn}$ as the basic material shows acceptable comprehensive performance. The results of the proposed sintering and material screening methods can provide a theoretical reference for developing cutters with satisfactory wear resistance and high rock breaking efficiency, which are commonly used in developing high-quality cutters.

\section{Acknowledgements}

This work was supported by the 13th Five-year Plan of Major National Special Projects of China (Grant no. 2016ZX05003-004-006).

This is an Open Access article distributed under the terms of the Creative Commons Attribution License.

\section{References}

1. Zhang, J., "Study and Practice of Drilling Technology". Xuzhou: China University of Mining and Technology Press, China, 2013.

2. Yu, J., Zou, D., Liu, X., "Design and application of novel hybrid drill bit for hard formation with strong abrasivity". Diamond \& Abrasives Engineering, 40(3), 2020, pp.67-71.

3. Ma, Y., H., Z, Li, Q., Zhou, Y., Peng, S., "Cutter layout optimization for reduction of lateral force on PDC bit using Kriging and particle swarm optimization methods". Journal of Petroleum Science and Engineering, 163, 2018, pp.359-370.

4. Huang, K., Ai, Z., Yang, Y., Xie, Z., "The improved rock breaking efficiency of an annular-groove PDC bit". Journal of Petroleum Science and Engineering, 172, 2019, pp.425-435.

5. Boussahaba, H., Sugumar J., Vrnak, K., Benyoucef, L., Fadtare, A., Al-Shammari, A., Al-Failakawi, K., Dutta, A., Al-Khaldy, M., "New and advanced PDC bit design with innovative backup layout cutters helps extend bit life without sacrificing rate of penetration during a heterogeneous application, Northwest Kuwait". In: Proceedings of the International Petroleum Technology Conference, Dhahran, Saudi Arabia: IPTC, 2020, IPTC-20030-MS.

6. El-Gayar, M., Ali, T. S., Talaf, M. A., "Multilevel force-balanced cutting structure layout helped solve PDC bit dullness issues resulting from geosteering in thin reservoirs". In: Proceedings of the SPE Bergen One Day Seminar, Bergen, Norway: SPE, 2017, SPE-185934MS.

7. Yu, J., Zou, D., Sun, Y., Zhang, Y., "Simulation and experimental study of the rock breaking mechanism of personalized polycrystalline diamond compact bits". Journal of Engineering Science and Technology Review, 13(3), 2020, pp.122-13.

8. Niu, S., Zheng, H., Yang, Y., Chen, L., "Experimental study on the rock-breaking mechanism of disc-like hybrid bit". Journal of Petroleum Science and Engineering, 161, 2018, pp.541-550.

9. Miyazaki, K., Ohno, T., Karasawa, H., Imaizumi, H., "Performance of polycrystalline diamond compact bit based on laboratory tests assuming geothermal well drilling”. Geothermics, 80, 2019, pp.185194.

10. Yu, J., Zou, D., Zhang, Y., "Analysis of rock dynamic stresses during the drilling by polycrystalline diamond compact bits". International Journal of Simulation Modelling, 19(4), 2020, pp.607618 .

11. Kamatov K., "Hybrid drill bit for horizontal drilling in highly interbedded formations of Timano-Pechora arctic fields". In: Proceedings of the SPE Arctic and Extreme Environments Technical Conference and Exhibition, Moscow, Russia: SPE, 2013, SPE166841-MS.

12. Garcia, A., Barocio, H., John, D., Perez Avila, E. A., "Hybrid bit technology expands application range in harsh rock environments". In: Proceedings of the SPE/IADC Middle East Drilling Technology Conference \& Exhibition, Dubai, UAE: SPE, 2013, SPE-166766-MS.
13. He, R., "Numerical simulation study on stinger PDC cutter's cutting rock process". Master thesis of China University of Petroleum (East China), China, 2014, pp.21-29.

14. Agawani, W., Al-Enezi, D. R., Pandya, M., Gupta, P., Abdelhamid, A., Al-Habib, H., El-Touny, S., "Engineered hybrid drill bit technology doubles drilling performance in impact-prone carbonates heavy oil application". In: Proceedings of the SPE International Heavy Oil Conference and Exhibition, Kuwait City, Kuwait: SPE, 2018, SPE-193704-MS

15. Mazen, A. Z., Mujtaba, I. M., Hassanpour, A., Rahmanian, N., "Mathematical modelling of performance and wear prediction of PDC drill bits: Impact of bit profile, bit hydraulic, and rock strength". Journal of Petroleum Science and Engineering, 188, 2020, pp.106849.

16. Yu, J., Zou, D., Liu, X., "A novel diamond hybrid bit improved performance in hard and abrasive formations". In: Proceedings of the 53rd U.S. Rock Mechanics/Geomechanics Symposium, New York, USA: ARMA, 2019, ARMA-2019-1898.

17. Abbas, R. K., Musa, K. M., "Using Raman shift and FT-IR spectra as quality indices of oil bit PDC cutters". Petroleum, 5, 2019, pp.329334.

18. Wang, X., Liu, Z., Qu, S., Su, C., "Research on rock breaking simulation of PDC bit under rock property parameters in Weibei Oilfield". China Energy and Environmental Protection, 40(9), 2018, pp.99-103.

19. Saksala, T., Gomon, D., Hokka, M., Kuokkala, V., "Numerical and experimental study of percussive drilling with a triple-button bit on Kuru granite”. International Journal of Impact Engineering, 72, 2014, pp.56-66.

20. Abbas, R. K., "A review on the wear of oil drill bits (conventional and the state of the art approaches for wear reduction and quantification)". Engineering Failure Analysis, 90, 2018, pp.554-584.

21. Wang, B., Li, J., Zou, D., Yang, H., Wang, K., "Design and application of a PDC hybrid drill bit with impregnated diamond insert for the hard formation with strong abrasivity". Special Oil and Gas Reservoirs, 25 (1), 2018, pp.169-174.

22. Galarraga, C., Fierro, J. C., AI Riyami, I., AI Salehi, Y., “An unconventional fixed cutter cutting structure layout to drill through hard , abrasive conglomerates in deep wells-a case study". In: Proceedings of the Abu Dhabi International Petroleum Exhibition \& Conference, Abu Dhabi, UAE: SPE, 2016, SPE-182879-MS.

23. Zheng, Y., "Effect of temperature and heating time on properties of diamond". Diamond Products and Stone Processing Information, 3, 1994, pp.36-40. 